\title{
MELHORAMENTO DO TRIGO. VIII. ASSOCIAÇÕES ENTRE PRODUÇÃO DE GRÃOS E OUTROS CARACTERES AGRONÔMICOS EM POPULAÇÕES HÍBRIDAS ENVOLVENDO DIFERENTES FONTES DE NANISMO (1)
}

\author{
CARLOS EDUARDO DE OLIVEIRA CAMARGO (2). Seçāo de Arroz e Cereais de Inverno, \\ Instituto Agronómico.
}

\begin{abstract}
RESUMO
Foram estimados os valores da herdabilidade para várias características da planta do trigo (comprimento da espiga, número de espiguetas por espiga, número de grãos por espiga e de grãos por espigueta, peso de cem grãos, número de espigas por planta, altura das plantas e produção de grãos), bem como as correlações entre produção de grãos e os demais caracteres agronômicos. Os estudos foram realizados em cruzamentos entre o cultivar $\mathrm{C}-3$, de porte alto, e os cultivares Tordo, Vican-71 e Olesen, de porte anão, e 'Siete Cerros', de porte semi-anão. Sementes representando os pais e as geraçóes $F_{7}$ e $F_{q}$ e os retrocruzamentos para ambos os pais foram utilizados em um ensaio, em blocos ao acaso, com quatro repetiçōes, conduzido na Estação Experimental de Itararé, do Instituto Agronómico. Os dados foram coletados na base de plantas individuais. A herdabilidade no sentido amplo, para número de espiguetas por espiga e altura das plantas foi, respectivamente, 0,533 e 0,525 , enquanto para comprimento da espiga, número de grãos por espiga e de grãos por espigueta, peso de cem grãos e número de espigas por planta, os valores observados variaram de
\end{abstract}

(1) Com verba suplementar do Acordo do Trigo entre as Cooperativas de Produtores Rurais do Vale do Paranapanema e a Secretaria de Agricultura e Abastecimento, por meio do Instituto Agronômico. Recebido para publicação a 19 de agosto de 1983.

(2) Com bolsa de suplementação do CNPq. 
0,339 a 0,473. Para produção de grãos a estimativa obtida da herdabilidade no sentido amplo foi 0,255 . Os valores da herdabilidade no sentido restrito, para os caracteres estudados, com exceção do número de espigas por planta, mostraram que grande parte da variabilidade de origem genética encontrada nas populações está também associada a uma ação aditiva dos genes. As correlações fenotípicas entre a produção de grãos e todos os demais caracteres agronônicos foram positivas e significativas ao nivel de $1 \%$ para quase todas as populaçōes estudadas. Constituíram exceções as correlações fenotipicas entre produção de grãos e número de espiguetas por espiga para as populações C-3 x Siete Cerros e C-3 X Vican-71; entre produção de grãos e peso de cem grãos para a população C-3 x Siete Cerros, e entre produção de grãos e número de grãos por espigueta para as populações C-3 $x$ Siete Cerros, C-3̀ $\mathrm{x}$ Tordo, e C-3 x Olesen, que toram também positivas, porém significativas apenas ao nivel de $5 \%$.

\section{INTRODUÇÃO}

Os cultivares de trigo semi-anões aumentaram significativamente a produção potencial de grãos, principalmente mediante maior resistência ao acamamento, porém não são adaptados às condições de solo ácido, onde estão presentes altos níveis de alumínio solúvel ou trocável.

CAMARGO \& OLIVEIRA (4) estudaram o cultivar de porte alto IAC-5 cruzado com os cultivares anãos Tordo, Vican-71 : Olesen e com o cultivar semi-anão Siete Cerros, os cultivares pais, os $F_{1}$ 's, os $F_{2}$ 's e os retrocruzamentos para ambos os pais, plantados em um ensaio em Itararé. Concluíram, os autores, que os cultivares escolhidos apresentaram um largo espectro de diversidade genética, para altura dass plantas, número de espiguetas por espiga, comprimento do internódio da raque, comprimento da espiga, número de espigas por planta, número de grãos por espigueta e por espiga. Concluíram, também, que nas populações estudadas, plantas altas foram associadas, significativamente, com maior produção de grãos por planta; maior número de espigas por planta, de espiguetas por espiga e de grãos por espiga; grãos mais pesados e espigas mais longas. Com o propósito de obter plantas de porte médio com alto potencial de produção, poderia ser utilizada qualquer uma das fontes de nanismo estudadas, desde que grandes populações $F_{2}$ fossem plantadas para assegurar maior freqüência de recombinantes desejáveis.

O presente trabalho teve por objetivo confirmar os resultados mencionados e conseguir novas informaçōes a respeito do comportamento das diferentes fontes genéticas de nanismo, em cruzamento com um cultivar de trigo de porte alto, visando à utilização no programa de melhoramento de trigo do Instituto Agronômico.

\section{MATERIAL E METODOS}

Para o presente trabalho, foram realizados cruzamentos entre o cultivar C-3 $\left(\mathrm{P}_{1}\right)$ e os cultivares Tordo $\left(\mathrm{P}_{2}\right)$, Olesen $\left(\mathrm{P}_{5}\right)$, Vican-71 $\left(\mathrm{P}_{4}\right)$ 
e Siete Cerros $\left(\mathrm{P}_{5}\right)$. O 'C-3' é de porte alto, o 'Tordo' é portador da fonte de nanismo "Tom Thumb"; 'Vican-71' e 'Siete Cerros' são oriundos da fonte de nanismo Norin-10 x Brevor-14, e o 'Olesen' é outra fonte de nanismo diferente das anteriores.

Além dos pais, integraram o ensaio as geraçōes $F_{1} \in F_{2}$ dos cruzamentos entre C-3 $\times$ Tordo $\left(\mathrm{P}_{1} \times \mathrm{P}_{2}\right)$; C-3 $\mathrm{x}$ Olesen $\left(\mathrm{P}_{1} \times \mathrm{P}_{3}\right) ; \mathrm{C}-3 \times$ Vican-71 $\left(P_{1} \times P_{4}\right)$ e $C-3 \times$ Siete Cerros $\left(P_{1} \times P_{5}\right)$, e as populações $F_{1}$ dos retrocruzamentos para ambos os pais, a saber: $\left(\mathrm{P}_{1} \times \mathrm{P}_{2}\right) \times \mathrm{P}_{1}$;

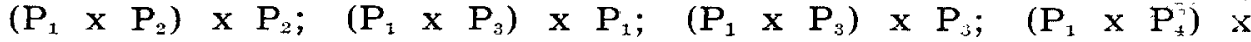
$\mathrm{P}_{1} ; \quad\left(\mathrm{P}_{1} \times \mathrm{P}_{4}\right) \times \mathrm{P}_{4} ; \quad\left(\mathrm{P}_{1} \times \mathrm{P}_{5}\right) \times \mathrm{P}_{1} \mathrm{e}\left(\mathrm{P}_{1} \times \mathrm{P}_{5}\right) \times \mathrm{F}_{5}$.

No ensaio, instalado na Estação Experimental de Itararé, do Instituto Agronômico, utilizou-se o delineamento experimental de blocos ao acaso com quatro repetições. Cada repetição foi constituída de quatro linhas de cada um dos híbridos em geração $\mathrm{F}_{2}$; três linhas de cada urn dos retrocruzamentos; duas linhas de cada cultivar empregado como progenitor e uma linha de cada um dos hibridos em geraçăo $F_{1}$. Em cadid linha, foram conduzidas doze plantas espaçadas $0,20 \mathrm{~m}$ uma da outra. A primeira e a última planta de cada linha, bem como a primeira e a última linha de cada bloco, constituíram bordaduras, plantadas com o cultivar BH-1146.

Os dados, coletados individualmente para cada planta, basearam-sc nos caracteres seguintes:

Altura das plantas - Medida, em centímetros, da superfície do solo até a ponta da espiga do colmo mais alto, excluindo as axistas.

Espigas por planta -- Computado somente o número de colmos com espigas férteis.

Produção de grãos - Peso, em gramas, da produçĩo total de grãos de cada planta.

Comprimento da espiga - Medida, em centímetros, da espiga do colmo principal, excluindo-se aristas.

Espiguetas - Considerado o número de espiguetas na espiga do colmo principal.

Grãos por espiga - Número total de grãos da espiga do colmo principal.

Grãos por espigueta - Número calculado pela divisão do total de grãos da espiga principal pelo total de espiguetas da mesma espiga. planta.

Peso de cem grãos - Peso de cem grãos tomados ao acaso de cada

Todos os caracteres estudados foram sujeitos à análise de variância, e o teste $F$ foi utilizado para determinar diferenças significativas. A média das plantas de cada parcela foi usada na análise, sendo os efeitos 
dos genótipos, divididos em componentes para detectar diferenças dentro de e entre geraçōes.

As estimativas da herdabilidade em sentido amplo (proporção entre a variância genética total e a variância fenotípica) foram calculadàs segundo o método citado por BRIGGS \& KNOWLES (1) e as estimativas da herdabilidade em sentido restrito (proporção entre a variância genética aditiva e a fenotípica), pelo método de WARNER (y). As estimativas da herdabilidade em sentido restrito foram também estimadas pela regressão da média dos $F_{2}$ 's sobre os respectivos $F_{1}$ 's, segundo FALCONER (5).

Os coeficientes de determinação foram obtidos pela correlação das médias dos $F_{2}$ 's e dos $F_{1}$ 's correspondentes, conforme FALCONER (5).

As correlações fenotípicas, ambientes e genéticas foram usadas para estimar o grau de associação entre produção de grãos e sete outros caracteres agronômicos para cada população. Como sugerido por FALCONER (5), as correlações usando dados de $F_{1}$ foram consideradas ambientes; aquelas empregando dados de $F_{2}$, correlações fenotípicas, sendo as genéticas calculadas por meio da seguinte fórmula:

$$
r_{F}=\sqrt{H_{x}} \sqrt{H_{y}} r_{G}+\sqrt{E_{x}} \sqrt{E_{y}} r_{.}
$$

onde: $r_{\mathrm{F}}=$ correlação fenotípica entre os caracteres $\mathrm{x} \in \mathrm{y} ; \mathrm{r}_{\mathrm{A}}=$ correlação ambiente entre os mesmos caracteres; $\mathrm{H}=$ herdabilidade em sentido restrito com subscritos $\mathrm{x}$ ou y conforme o caráter; $\mathrm{E}=1-\mathrm{H}$, também como subscritos de acordo com o caráter estudado.

\section{RESULTADOS E DISCUSSÃO}

As análises de variância para os caracteres estudados encontram-se no quadro $1 \mathrm{e}$ as médias de cada genótipo para cada um desses caracteres, no quadro 2.

Aplicando o teste de Tukey a 5\%, verificou-se que o cultivar C-3 apresentou as espigas mais compridas, diferindo dos demais, e o 'Olesen', as mais curtas, diferindo também dos outros. Não foram detectadas diferenças entre Siete Cerros e Tordo, porém este apresentou espigas mais longas, diferindo de Vican-71. Siete Cerros também apresentou espigas mais compridas que Vican-71, porém a diferença não foi significativa. Comparando as médias das quatro populações em geração $F_{1}$, a proveniente do cruzamento $\mathrm{C}-3 \times$ x Siete Cerros foi a que apresentou espigas mais compridas, diferindo das médias das populações $\mathbf{F}_{1}$ de $\mathrm{C}-3 \times$ vican-71 e C-3 x Olesen. A média da população em geração $F_{z}$ do cruzamento C-3 $\times$ Tordo foi a que mostrou espigas mais longas, diferindo das populações oriundas dos cruzamentos C-3 x Vican-71 e C-3 x Olesen, porém não de C-3 x Siete Cerros. Não foram detectadas diferenças significativas entre os retrocruzamentos para o cultivar $\mathrm{C}-3\left(\mathrm{RC}_{3}\right.$ 's). Pelas médias dos retrocruzamentos para as diferentes fontes de nanismo $\left(\mathrm{RC}_{2}\right.$ 's), - (C-3 x Siete Cerros) x Siete Cerros mostrou espigas mais compridas, diferindo dos demais $\mathrm{RC}_{2}$ 's, à exceção do $(\mathrm{C}-3 \mathrm{x}$ Tordo $) \times$ Tordo. 


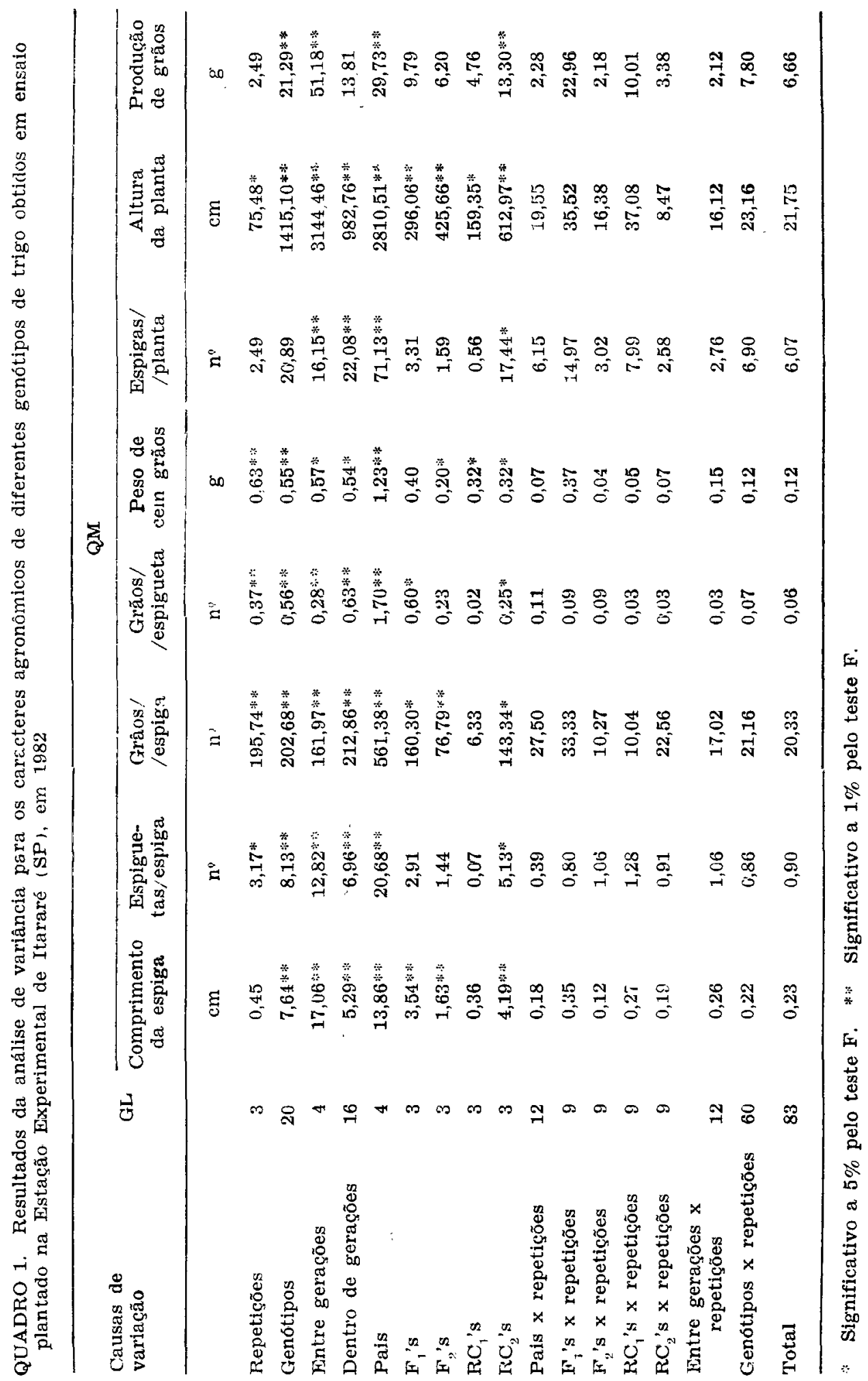




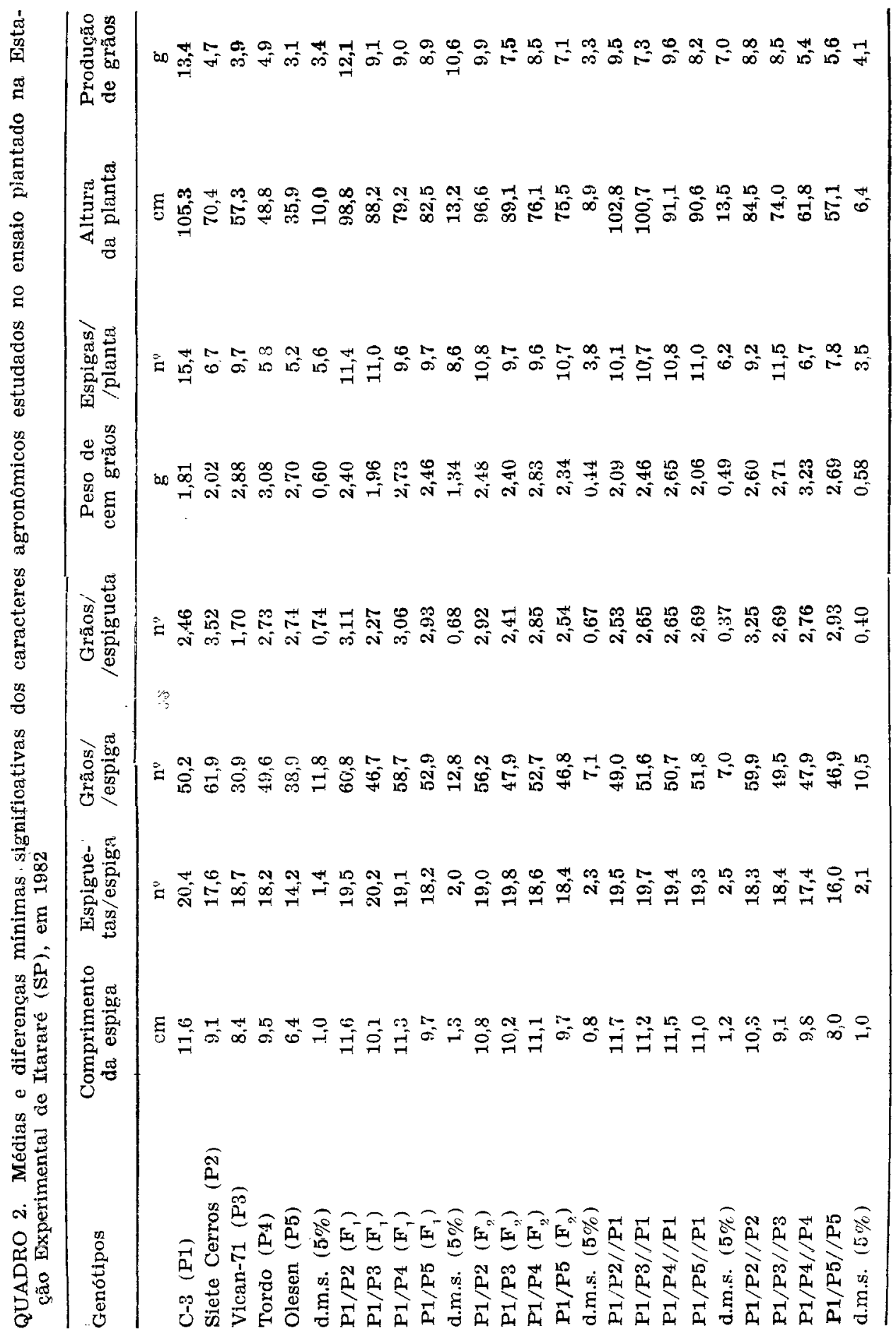


Considerando o número de espiguetas por espiga, o cultivar $\mathrm{C}-3$ apresentou maior índice e, o Olesen, o menor, ambos diferindo estatisticamente dos demais. Não foram detectadas diferenças $\epsilon$ ntre as populações $F_{1}, F_{2}$ e $\mathrm{RC}_{1}$ 's. Entre os $\mathrm{RC}_{2}$ 's, (C-3 x Vican-71) $\mathrm{x}$ Vican-71 foi o que apresentou maior número de espiguetas por espiga, diferindo significativamente, porém, apenas do retrocruzamento (C-3 x Olesen) $\mathrm{x}$ Olesen.

O cultivar Siete Cerros foi o que apresentou maior nịmero de grãos por espiga, diferindo dos demais, à exceção do C-3. A população em geração $F_{1}$ oriunda do cruzamento $C-3 \times$ Siete Cerros apresentou maior número de grãos por espiga, porém diferiu estatisticamente apenas da prọveniente do cruzamento C-3 x Vican-71. A população em geração $\mathrm{F}_{2}$, resultante do híbrido $\mathrm{C}-3 \mathrm{x}$ Siete Cerros, mostrou maior número de grãos por espiga em relação às demais; não diferiu estatisticamente, porém, daquela provinda do cruzamento C-3 x Tordo. Não foram observadas diferenças significativas entre os $R C_{1}$ 's em relação ao número de grãos por espiga. Entre os retrocruzamentos para as diferentes fontes de nanismo, (C-3 x Siete Cerros) $\mathrm{x}$ Siete Cerros foi o que apresentou maior número de grãos por espiga, diferindo significativamente dos demais. Como já observado em trabalho anterior (4), o cultivar Siete Cerros em cruzamentos mostrou-se promissor para transmitir a descendentes a característica maior número de grãos por espiga.

Considerando o número de grãos por espigueta, o cultivar Siete Cerros apresentou maior média e o Vican-71, a menor, diferindo ambos estatisticamente dos demais. A população $F_{1}$ do híbrido $C-3 \times$ Siete Cerros produziu maior número de grãos por espigueta do que as demais, porém só diferiu estatisticamente do híbrido C-3 x Vican-71. Não foram verificadas diferenças significativas para este caráter nas populações $\mathrm{F}_{2}$ 's e $\mathrm{RC}_{1}$ 's. A população do retrocruzamento (C-3 $\mathrm{x}$ Siete Cerros) $\mathrm{x}$ Siete Cerros apresentou maior número de grāos por espigueta, só não diferindo estatisticamente do hibrido ( $\mathrm{C}-3 \mathrm{x}$ Olesen) $\mathrm{x}$ Olesen. Como jä observado em trabalho anterior (4), o Siete Cerros apresentou grande potencial em transferir para suas progênies a característica maior número de grãos por espigueta.

O Tordo apresentou grãos mais pesados, sendo estatisticamente superior, porém, apenas, aos cultivares C-3 x Siete Cerros. Não foram detectadas diferenças significativas com relação ao peso de cem grãos para as diferentes populações $F_{1}$ em estudo. $O$ híbrido $C-3 \times$ Tordo em geração $F_{2}$ foi o que mostrou grãos mais pesados, porém somente diferiu do $\mathrm{C}-3 \mathrm{x}$ Olesen. Entre os $\mathrm{RC}_{1}$ 's verificou-se que $(\mathrm{C}-3 \times$ x Tordo $) \times \mathrm{C}-3$ apresentou o maior peso de cem grãos, diferindo dos demais retrocruzamentos para o progenitor C-3, exceto (C-3 x Vican-71) x C-3. Com exceção aos $\mathrm{RC}_{2}$ 's, o retrocruzamento ( $\mathrm{C}-3 \mathrm{x}$ Tordo) $\mathrm{x}$ Tordo apresentou grãos mais pesados, porém somente diferiu significativamente do híbrido (C-3 x Siete Cerros) $x$ Siete Cerros. Os resultados indicaram que o Tordo poderia ser utilizado como fonte de grãos mais pesados no pro- 
grama de melhoramento genético, em virtude de se mostrar eficiente em transmitir essa característica às suas progênies.

Com relação ao número de espigas por planta, C-3̇ apresentou a maior média, diferindo estatisticamente dos demais. Não foram observadas diferenças significativas entre os $F_{1}$ 's, $F_{2}$ 's e $R_{1}$ 's em relação a essa característica. Pelas médias dos $\mathrm{RC}_{2}$ 's verifica-se que a originária de (C-3 x Vican-71) x Vican-71 apresentou maior número de espigas por planta, diferindo estatisticamente, porém, só de (C-3 x Tordo) $\mathrm{x}$ Tordo e (C-3 x Olesen) x Olesen. O cultivar C-3 mostrou-se fonte genética de grande valor para ser utilizada em programas de melhoramento que objetivem maior número de espigas por planta.

Esse cultivar foi o mais alto, diferindo significativamente dos demais, e o semi-anāo Siete Cerros, o mais alto entre as fontes de nanismo em estudo, diferindo significativamente dos anãos Tordo, Vican-71 e Olesen. Este foi o mais baixo, diferindo estatisticamente de todos os pais estudados, enquanto Tordo e Vican-71 não diferiram entre si. Esses resultados confirmaram os obtidos por CAMARGO \& OLiVEIRA (3). Comparando as médias dentro das populações $F_{2}$ e $F_{2}$, o cruzamento $\mathrm{C}-3 \mathrm{x}$ Siete Cerros apresentou plantas mais altas, diferindo do C-3 x Tordo e C-3 x Olesen, porém não mostrando diferenças significativas em relação ao cruzamento C-3 x Vican-71. Pelas médias dos $\mathrm{RC}_{1}$ 's não foram notadas diferenças significativas em àtiura entre os genótipos. No concernente às geraçōes $\mathrm{RC}_{2}$, o retrocruzamento $(\mathrm{C}-3 \mathrm{x}$ Siete Cerros) $\mathrm{x}$ Siete Cerros apresentou as plantas mais altas, diferindo dos demais. O retrocruzamento (C-3 $x$ Vican-71) $x$ Vican-71 mostrou plantas significativamente mais altas do que (C-3 $\mathbf{x}$ Tordo) $\mathrm{x}$ Tordo e (C-3 x Olesen) $x$ Olesen que, por sua vez, não diferiram estatisticamente.

Em relação à produção de grāos o cultivar C-3, de grande adaptação a solos ácidos, foi significativamente superior aos c̉emais, que não diferiram entre si. Não foram detectadas diferenças significativas pelo teste de Tukey quando comparadas as médias dos genótipos nas gerações $F_{1}$ e $F_{2}$ e entre os retrocruzamentos, apesar de as médias da maioria dos genótipos nas populações $F_{1}$ e $F_{z}$ serem superiores às médias de ambos os pais, evidenciando heterose para esse caráter. Resultados semelhantes foram encontrados por JOHSON et alii (6), CAMARGO et alii (2) e CAMARGO \& OLIVEIRA (4), confirmando a grande influência do ambiente sobre a produção de grãos de plantas individuais, mesmo em condiçōes adequadas de população de plantas por área.

As estimativas das herdabilidades em sentido amplo $\left(\mathrm{H}_{\mathrm{BS}}\right)$ e sentido restrito $\left(\mathrm{H}_{\mathrm{Ns}}\right)$ e os coeficientes de determinação $\left(\mathrm{R}^{2}\right)$ para todos os caracteres estudados, derivadas de dados obtidos nas gerações parentais, $\mathrm{F}_{1}$ 's, $\mathrm{F}_{2}$ 's e retrocruzamentos das quatro populações híbridas, encontram-se no quadro 3 . 
QUADRO 3. Estimativas das herdabilidades em sentido amplo $\left(\mathrm{H}_{B \mathrm{~S}}\right)$ e sentido restrito $\left(\mathrm{H}_{\mathrm{vg}}\right)$ e os coeficientes de determinação $\left(\mathrm{R}_{2}\right)$ para tccios os caracteres estudacios, derivadas de dados obtidos nas gerações parentais, $F_{1}$ 's, $F_{2}$ 's, $R C_{1}$ 's e $\mathrm{KC}$,'s, de cruzamentos entre $\mathrm{C} 3$, um cultivar de trigo de porte alto, e quatro uutros cultivares fontes de nanismo

\begin{tabular}{|c|c|c|c|c|}
\hline \multirow{2}{*}{ Caráter } & \multirow{2}{*}{$\mathrm{H}_{\mathrm{BS}}$} & \multicolumn{2}{|c|}{$\mathrm{H}_{\mathrm{NS}}$ (I) } & \multirow{2}{*}{$R:$} \\
\hline & & Método 1 & Metodo 2 & \\
\hline Comprimento da espiga & 0,334 & 0,292 & 0,532 & $0,675^{*: *}$ \\
\hline Espiguetas/espiga & 0,533 & 0,445 & 0,503 & $0,253^{*}$ \\
\hline Grãos/espiga & 0,473 & 0,182 & 0,452 & $0,362^{\text {; }}$ \\
\hline Grãos/espigueta & 0.459 & - & 0,396 & $0,460 *$ \\
\hline Peso de cem grãos & 0,339 & 0,144 & 0,253 & 0,162 \\
\hline Espigas/planta & 0,402 & - & 0,086 & 0,026 \\
\hline Altura da planta & 0,525 & 0,356 & 0,815 & $0,615 *$ \\
\hline Produção de grãos & 0,255 & - & 0,170 & 0,174 \\
\hline
\end{tabular}

(1) O método 1 foi proposto por Warner e, o 2, estimado pela regressão do $F_{2}$ sobre o $F_{1}$, por Falconer.

* Significativo ao nivel de $5 \%$ * Significativo ao nivel de $1 \%$.

Os valores estimados para a herdabilidade em sentido amplo foram médios para: número de espiguetas por espiga, de grãos por espiga, de grãos por espigueta, de espigas por planta, e altura da planta, e baixos para os caracteres comprimento da espiga, peso de cem grãos e produção de grãos. Esses valores indicam que grande parte das variâncias obtidas para os primeiros caracteres mencionados são de origem genética, nas populações estudadas.

Não foram estimados os valores da herdabilidade em sentddo restrito pelo método de WARNER ( $\boldsymbol{y})$ para os caracteres espigas por planta, produção de grãos e número de grãos por espigueta, devido a uma variância elevada para os retrocruzamentos em relação às populações $F_{2}$ para os dois primeiros caracteres e, para número de grãos por espigueta, devido a se ter obtido uma variância para as populações $F_{z}$ muito superior às encontradas para os retrocruzamentos, talvez devido ao tamanho relativamente pequeno das populações estudadas.

Os valores da herdabilidade em sentido restrito estimados peio método de WARNER ( $\boldsymbol{\gamma}$ ) foram menores do que aqueles calculados pelc da regressão das médias dos $F_{2}$ 's sobre as médias dos $F_{1}$ 's, para os caracteres considerados. Todos os valores estimados para a herdabilidade em sentido restrito foram menores do que aqueles estimados para os mesmos caracteres para a herdabilidade em sentido amplo, à exceção da altura das plantas e do comprimento da espiga, que foram superestimados pelo método da regressão. 
$O$ valor da herdabilidade em sentido restrito para altura das plantas pelo método da regressão das médias dos $F_{2}$ 's sobre os $F_{1}$ 's indica que grande parte da variabilidade genética total está associada a uma ação aditiva de genes. Como também foi obtido um coeficiente de determinação para altura das plantas de 0,615, altamente significativo, os dados sugeriram que a seleção para esse caráter seria efetiva nas gerações $F_{2}$ ou $F_{3}$, confirmando resultados obtidos anteriormente $(\boldsymbol{2}, \mathbf{3}, \mathbf{4})$.

Os demais caracteres agronômicos, exceto número de espigas płr planta, demonstram que a variabilidade de origem genética encontrada nas populações estava também associada a uma ação aditiva dos genes. Valores significativos dos coeficientes de determinação calculados para comprimento da espiga, número de espiguetas por espiga, número de grãos por espiga, número de grãos por espigueta e aitura das plantas indicaram que uma alta porcentagem da variabilidade observada parí esses caracteres nas progênies seria proveniente da variação encontrada nos pais, sugerindo que as seleções para eles seriam eficientes nas primeiras gerações segregantes, porém, devido ao fato de uma elevada parte da variação total encontrada ser de origem ambiente, a seleção para esses caracteres e para peso de cem grãos, número de espigas por planta e produção de grãos que apresentaram coeficientes de determinação baixos e não-significativos, deveria ser efetuada nas últimas gerações quando o valor genético da progênie poderia ser mais precisamente determinado.

As correlações ambientes $\left(r_{A}\right)$, fenotípicas $\left(r_{F}\right)$ e genéticas $\left(r_{i}\right)$ entre a produção de grãos e os outros sete caracteres agronômicos estudados encontram-se no quadro 4 .

As correlaçōes fenotípicas entre a produção de grãos e todos os demais caracteres agronômicos foram positivas e altamente significativas, fazendo exceção aquelas entre produção de grãos e nümero de espiguetas por espiga para as populações C-3 x Siete Cerros e C-3 x Vican-71, que foram positivas e significativas ao nivel de $5 \%$; entre produção de grãos e peso de cem grãos para a população C-3 x Siete Serros, que foi positiva e significativa ao nível de $5 \%$, e entre produção de grãos e número de grãos por espigueta para as populações C-3 x Siete Cerros, C-3 x Tordo e C-3 x Olesen, que foram também positivas $*$ significativas ao nivel de $5 \%$.

Considerando populações provenientes dos cruzamentos entre o cultivar $\mathrm{C}-3$ e as diferentes fontes de nanismo, verificou-se que plantas altas estão associadas com as maiores produções de grãos. Como o objetivo do programa de melhoramento é a obtenção de plantas de porte médio, com alto potencial de produção, seriam necessárias grandes populações $\mathrm{F}_{2}$ para assegurar maior freqüência de recombinantes desejáveis. 
QUADRO 4. Correlações ambientes $\left(r_{A}\right)$, fenotípicas $\left(r_{F}\right)$ e genéticas $\left(r_{F_{F}}\right)$ entre a produção de grãos e sete outros caracteres agronômicos para cruzamentos de trigo envolvendo o cultivar $\mathrm{C}-3$, de porte alto, e quatro cultivares de porte baixo

\begin{tabular}{|c|c|c|c|c|c|}
\hline $\begin{array}{l}\text { Caráter correla- } \\
\text { cionado com pro- } \\
\text { dução de grãos }\end{array}$ & & $\begin{array}{c}\mathbb{C - 3} \times \\
\text { Siete Cerros }\end{array}$ & $\begin{array}{l}\text { C-3 } x \\
\text { Tordc }\end{array}$ & $\begin{array}{c}\text { C-3 x } \\
\text { Olesen }\end{array}$ & $\begin{array}{c}\text { C-3 x } \\
\text { Vican-71 }\end{array}$ \\
\hline $\begin{array}{l}\text { Comprimento } \\
\text { da espiga }\end{array}$ & $\begin{array}{l}r_{A} \\
r_{\mathrm{g}} \\
r_{\mathrm{g}}\end{array}$ & $\begin{array}{l}0,316 \\
0,246: 5 \\
0,163\end{array}$ & $\begin{array}{l}0,609^{*: ;} \\
0,328 *: \\
-\quad 0,171\end{array}$ & $\begin{array}{l}0,566 * * \\
0,316^{* *} \\
-0.122\end{array}$ & $\begin{array}{l}0,583 * ; \\
0,388 ; * \\
0,082\end{array}$ \\
\hline $\begin{array}{l}\text { Espiguetas/ } \\
\text { /espiga }\end{array}$ & $\begin{array}{l}r_{1} \\
r_{k} \\
r_{0}\end{array}$ & $\begin{array}{l}0,120 \\
0,225 \% \\
0,584\end{array}$ & $\begin{array}{l}0,467 * \\
0,280 * \% \\
0,234\end{array}$ & $\begin{array}{l}0,361 \\
0,288^{*} \\
0,426\end{array}$ & $\begin{array}{l}0,512 * \\
0,213 * \\
0,065\end{array}$ \\
\hline Grãos/espiga & $\begin{array}{l}r_{i} \\
r_{F} \\
r_{r}\end{array}$ & 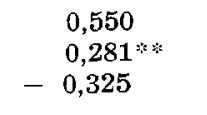 & $\begin{array}{l}0,589 \% * \\
0,329 \% * \\
-0,277\end{array}$ & $\begin{array}{l}0,645 * \\
0,530 \\
0,343\end{array}$ & $\begin{array}{l}0,551 \text {; } \\
0,494 \text { * } \\
0,442\end{array}$ \\
\hline $\begin{array}{l}\text { Peso de cem } \\
\text { grãos }\end{array}$ & $\begin{array}{l}\mathrm{r}_{\mathrm{A}} \\
\mathrm{r}_{\mathrm{F}} \\
\mathrm{r}_{\mathrm{G}}\end{array}$ & $\begin{array}{c}0,883^{*} \\
0,205^{*} \\
<-1,0\end{array}$ & $\begin{array}{c}0,703 * \% \\
0,317 * * \\
<-1,0\end{array}$ & $\begin{array}{ll} & 0,200 \\
& 0.488^{*} \\
> & 1,0\end{array}$ & $\begin{aligned} 0,779 * \\
0,315: * \\
<-1,0\end{aligned}$ \\
\hline $\begin{array}{l}\text { Grãos/ } \\
\text { /espigueta }\end{array}$ & $\begin{array}{l}r_{A} \\
r_{F} \\
r_{G}\end{array}$ & $\begin{array}{r}0,708^{*} \\
0,190^{*} \\
<-1,0\end{array}$ & $\begin{array}{l}0,520 * * \\
-0,212^{*} \\
-0,603\end{array}$ & 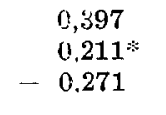 & $\begin{array}{l}0,522 * \\
0,443 ; \\
0,283\end{array}$ \\
\hline $\begin{array}{l}\text { Altura da } \\
\text { planta }\end{array}$ & $\begin{array}{l}r_{A} \\
r_{F} \\
r_{G_{r}}\end{array}$ & $\begin{array}{l}0,875 \approx \\
0,421 \approx \\
0,210\end{array}$ & $\begin{array}{l}0,701 * \% \\
0,518 * * \\
0,654\end{array}$ & $\begin{array}{l}0,699 * \\
0,308 * \\
0.285\end{array}$ & $\begin{array}{l}0,738 \\
0,429 \\
0,376\end{array}$ \\
\hline Espigas/planta & $\begin{array}{l}r_{A} \\
r_{F} \\
r_{f i}\end{array}$ & $\begin{aligned} & 0,969 * * \\
& 0,807 * * \\
&- 0,306\end{aligned}$ & $\begin{array}{l}0,937 * \approx \\
0,851 * * \\
0,288\end{array}$ & $\begin{array}{l}0,903^{*} \\
0,712^{*} \\
-0,615\end{array}$ & $\begin{array}{c}0,972 \\
0,677 \\
<-1,0\end{array}$ \\
\hline
\end{tabular}

$*$ Significativo ao nível de $5 \%$. $*$ Significativo ao nivel de $1 \%$

\section{SUMMARY}

\section{WHEAT BREEDING.}

\section{ASSOCIATIONS OF GRAIN YIELD WITH OTHER AGRONOMIC CHARACTERISTICS IN CROSSES INVOLVING DIFFERENT SOURCES OF DWARFISM IN WHEAT}

Standard height cultivar $\mathrm{C}-3$ was crossed with the semi-dwarf cultivar Siete Cerros and the dwarf cultivars Tordo, Vican-71 and Olesen. Parents, F', $\mathbf{F}$, F.'s and reciprocal back-crosses were tested for grain yield, plant height, number of spikes per plant, number of spikelets per spike, number of grains per spike, number of grains per spikelet, 100-grain-weight, spike length, in a experiment carried out at Itararé Experimental Station, State of São Paulo, Brazil. All data was determined on an individual plant basis. Broad sense heritability estimates for number of spikelets per spike and plant height were 0.533 and 0.525 , respectively. The values for spike length, number of grains per spike and spikelet, 100-grain-weight 
and number of spikes per plant showed variation between 0.339 and 0.473 . Broad sense heritability for grain yield was low and equal to 6.255 . Narrow sense heritability estimates for all characteristics under study except for number of spikes per plant showed that great part of the total genetic variation found in the studied populations was associated with additive gene action. The correlations between grain yield and all the other characteristics were positive and significant at $1 \%$ level probability, for all the populations under study, except for the correlations between grain yield and number of spikelets per spike for the populations C-3 $x$ Siete Cerros and C-3 x Vican-71, between grain yield and 100-grain-weight for the population C-3 $x$ Siete Cerros, between grains yield and number of grains per spikelet for the populations C-3 $\times$ Siete Cerros, C-3 $x$ Tordo and C-3 $x$ Olesen, which showed to be positive and significant only at the $5 \%$ probability level.

\section{REFERENCLAS BIBLIOGRAFFICAS}

1. BRIGGS, F.N. \& KNOWLES, P.F. Introduction to plant breeding. Davis, Reinhold Publishing Corporation, 1977. 426p.

2. CAMARGO, C.E.O.; KRONSTAD, W.E.; METZGER, R. Pareni-progeny regression estimates and associations of height levels with aluminum toxicity and grain yield in wheat. Crop Science, 20:355-358, 1980.

3. _ \& OLIVEIRA, O.F. Melhoramento do trigo. II. Estudo genético de fontes de nanismo para a cultura co trigo. Bragantia, Campinas, 40:77-91, 1981.

4. —_- Melhoramento do trigo. V. Estimativas das herdabilidades e correlaçōes entre altura, produção de grãos e outros caracteres agronômicos em trigo. Bragantia, Campinas, 42:131-148, 1983.

5. FALCONER, D.S. Introduction to quantitative genetics. New York, Ronald Press, 1960. 365p.

6. JOHNSON, V.A.; BIEVER, K.J.; HAUNOLD, A.; SCHMIDT, J.W. Inheritance of plant height yield of grain, and other plant and seed characteristics in a cross of hard red winter wheat (Triticum aestivum L.j. Crop Science, 6:336-338, 1966.

7. WARNER, J.N. A method for estimating heritability. Agronomy Journal, $7: 427-430,1952$. 